\title{
Hemorrhagic Complications after Endovascular Treatment of Cerebral Arteriovenous Malformations
}

\author{
H. Baharvahdat, R. Blanc, R. Termechi, S. Pistocchi, B. Bartolini, H. Redjem, and M. Piotin
}

\begin{abstract}
BACKGROUND AND PURPOSE: Intracranial hemorrhage is the most severe complication of brain arteriovenous malformation treatment. We report our rate of hemorrhagic complications after endovascular treatment and analyze the clinical significance and potential mechanisms, with emphasis on cases of delayed hemorrhage after uneventful embolization.
\end{abstract}

MATERIALS AND METHODS: During a 10-year period, 846 embolization procedures were performed in 408 patients with brain AVMs. Any cases of hemorrhagic complications were identified and divided into those related or unrelated to a periprocedural arterial tear (during catheter navigation or catheter retrieval). We analyzed the following variables: sex, age, hemorrhagic presentation, Spetzler-Martin grade, size of the AVM, number of embolized pedicles, microcatheter used, type and volume of liquid embolic agent injected, and the presence of a premature venous occlusion. Univariate and multivariate multiple regression analyses were performed to identify risk factors for hemorrhagic complications.

RESULTS: A hemorrhagic complication occurred in 92 (11\%) procedures. Forty-four (48\%) complications were related to a periprocedural arterial perforation, and 48 (52\%) were not. Hemorrhagic complications unrelated to an arterial perforation were located more commonly in the cerebral parenchyma, caused more neurologic deficits, and were associated with worse prognosis than those in the arterial perforation group. Only premature venous occlusion was identified as an independent predictor of hemorrhagic complication in the nonperforation group. Premature venous occlusion was significantly related to the ratio of Onyx volume to nidus diameter.

CONCLUSIONS: Higher injected volume of embolic agent and deposition on the venous outflow before complete occlusion of the AVM may account for severe hemorrhagic complications.

ABBREVIATIONS: AP = arterial perforation; $\mathrm{EVT}=$ endovascular treatment; $\mathrm{HC}=$ hemorrhagic complication; NAP = non-arterial perforation; $\mathrm{S}-\mathrm{M}=\mathrm{Spetzler-}$ Martin; $\mathrm{V}_{\mathrm{ea}}=$ volume of liquid embolic agents

T

reatment of cerebral arteriovenous malformation is challenging and requires a multidisciplinary approach involving surgery with AVM removal, endovascular treatment (EVT) with embolization, or radiosurgery. Each technique can be combined and has its own advantages and complications. A conservative approach is an important aspect of the management of AVMs. EVT can be used for presurgical or preradiosurgical treatment of AVMs or as a stand-alone procedure for curative purposes. Onyx (Covidien, Irvine, California) is currently the most commonly

Received July 29, 2013; accepted after revision September 29.

From the Department of Interventional Neuroradiology (H.B., R.B., S.P., B.B., H.R., M.P.), Fondation Adolphe de Rothschild, Paris, France; Neurosurgical Department (H.B.), Ghaem Hospital, Mashhad University of Medical Sciences, Iran; and Department of Neurology (R.T.), Vali-Asr Hospital, Tehran, Iran.

Please address correspondence to Raphaël Blanc, MD, MSc, Department of Interventional Neuroradiology Fondation Adolphe de Rothschild Hospital, Paris, France; e-mail rblanc@fo-rothschild.fr

http://dx.doi.org/10.3174/ajnr.A3906 used embolic agent; in some instances, cyanoacrylate glue can be used. The most serious complication of AVM embolization is hemorrhage, reported in $4 \%-15 \%$ of patients treated by EVT. ${ }^{1-3}$ The group of patients who experience delayed hemorrhage after EVT remains poorly understood, with multiple classifications ${ }^{4-6}$ and explanations $s^{7-9}$ and deserves further study. To investigate the potential mechanisms of hemorrhages following EVT, we report our rate of hemorrhagic complications (HCs) and their clinical significance and focus on those not related to an arterial lesion secondary to navigation or microcatheter retrieval.

\section{MATERIALS AND METHODS \\ Patients and AVM Characteristics}

Approval was obtained from our institutional ethics board to review the data from patients with AVMs who underwent endovascular procedures between January 2000 and March 2010. From our prospectively acquired data base, we collected patients' baseline characteristics, AVM modes of presentation, and total num- 
ber of sessions per patient. The preprocedural neurologic condition was recorded, and outcomes were measured according to the modified Rankin Scale at patient discharge from the hospital and at 1 month.

AVMs were classified according to the Spetzler-Martin (S-M) grade. ${ }^{10}$ The presence of intranidal aneurysms or aneurysms located on the arterial feeders to the malformations was recorded. The AVM venous outflow was scrutinized for venous ectasia or stenosis and the presence of a deep or single venous drainage. AVMs were localized as cortical, for cortical and subcortical supratentorial lesions; deep, for lesions located in the basal ganglia, thalamus, corpus callosum, and internal capsules; and infratentorial.

\section{Endovascular Procedure}

At our institution, patients were allocated to a treatment technique after multidisciplinary discussion, with EVT (with the goal of complete obliteration of the nidus in 1 or multiple sessions) being the first-choice treatment for cerebral AVMs. In very large cerebral AVMs, the objective was to reduce the risk of hemorrhage, seizure, and neurologic symptoms or to reduce the size of the nidus to permit another treatment technique. EVTs were performed with the patient under general anesthesia according to our standard protocol. In the study period, Onyx was the most commonly used agent for embolization of AVMs. Occasionally, cyanoacrylate glue (Histoacryl; Braun, Melsungen, Germany) or Glubran2 (GEM, Viareggio, Italy) was injected during the procedure for high-flow fistulas or arterial perforation. The number of pedicles catheterized and the total volume of liquid embolic agents (Onyx or cyanoacrylates) injected were recorded. For small or single-compartment AVMs, the procedure was stopped when complete occlusion was achieved or when there was $>2-\mathrm{cm}$ reflux of Onyx. For large AVMs, the goal was to embolize 30\%-50\% in 1 session. If necessary, multiple pedicles were embolized in 1 session. A head CT scan was performed (mobile CT scan until 2006, at which time the flat panel CT became available) in the operating room after each procedure or immediately if any perforation occurred.

After the procedure, all patients were admitted postoperatively to the intensive care unit with strict control of systolic blood pressure at $<110 \mathrm{~mm} \mathrm{Hg}$ for 24-48 hours. The patients were discharged within 4-5 days after embolization if there were no significant complications. The interval between the 2 procedures was 1-4 months. If an HC occurred, the patient was managed medically or surgically, depending on the volume of hematoma and the patient's condition. On the basis of the location of the hematoma, the surgery included hematoma evacuation or decompressive craniotomy. If patients were unconsciousness, intracranial pressure was monitored.

Data on procedural or postprocedural complications were collected, including catheter-related complications, the presence of a postembolization $\mathrm{HC}$, or ischemic events. The angiographic results of AVM exclusion were considered complete if the nidus was excluded with no residual arteriovenous shunt and incomplete if any residual venous drainage was visible. The pattern of a premature venous occlusion, defined as occlusion of the venous drainage before complete nidal exclusion (either spontaneously or secondary to deposition of liquid embolic), was recorded. EVT was considered "completed" if complete angiographic occlusion of AVM was achieved, if endovascular access to the AVM was no longer possible, or if patients were sent for radiosurgery or surgery to complete the treatment. EVT was considered "ongoing" if another session was scheduled.

\section{Hemorrhagic Complications}

Any HC (subarachnoid, intraventricular, intraparenchymal hemorrhage) that occurred during or within 1 month of embolization was recorded.

The cause of the hemorrhage was categorized as either of the following:

1) Arterial perforation (AP) when related to an arterial perforation during microcatheterization or microcatheter retrieval (shown by extravasation of contrast during the procedure or visible on the CT scan after the procedure)

2. Nonarterial perforation (NAP) if the hemorrhage was not caused by arterial perforation during the procedure.

\section{Statistical Analysis}

Descriptive statistics were used to summarize the baseline characteristics of the procedures, patients, and procedures with HC. Continuous data are presented as means \pm SDs. Statistical comparisons were performed by the $\chi^{2}$ test, Student $t$ test, and Fisher exact test for normally distributed data and the Mann-Whitney $U$ test for data not normally distributed. Univariate analysis was performed to identify the effect of sex, age, hemorrhagic presentation, largest nidus diameter, injected volume of Onyx in each procedure, total injected volume of liquid embolic agents including Onyx and glue in each procedure $\left(\mathrm{V}_{\mathrm{ea}}\right)$, ratio of Onyx volume to largest diameter of nidus, ratio of $\mathrm{V}_{\mathrm{ea}}$ to the largest diameter of the nidus, number of embolized pedicles, premature venous occlusion, and microcatheter used on HC in the NAP group. Multivariate analysis was performed by logistic regression to test the real effect of the variables identified as risk factors of $\mathrm{HC}$ in univariate analysis. Model selection was performed by a stepwise continuous procedure. A $P$ value $<.05$ was statistically significant. The data were analyzed by using the Statistical Package for Social Sciences (Version 16.0; IBM, Armonk, New York).

\section{RESULTS}

Between January 2000 and March 2010, four hundred eight patients with brain AVMs underwent 846 endovascular procedures; 230 were men $(56 \%)$, and the mean age was $33.3 \pm 14.1$ years. Table 1 shows the basic characteristics of the patients and the AVMs. The median number of procedures for each case was 2 (range, 1-12). Nineteen procedures failed due to inability to access the appropriate point for embolization. Of the 827 successful procedures, Onyx 18 was used in $669(81 \%)$ and cyanoacrylate in $251(30 \%)$, including both liquid embolic agents in $93(11 \%)$ sessions. The mean injected volume of Onyx in each procedure was $2.1 \pm 2.0 \mathrm{~mL}$. Of the 408 AVMs, EVT was completed in 282 (69\%). Complete obliteration was achieved in 198 AVMs (ie, 70\% AVMs with completed EVT or $49 \%$ of all AVMs). According to the Spetzler-Martin grade, overall cure (complete obliteration) 
was $87 \%$ in grade I, $82 \%$ in grade II, 55\% in grade III, 57\% in grade IV, and 50\% in grade V in 198 patients who completed EVT.

Overall, 22 (5\%) of the 408 patients were sent to radiosurgery, and $15(4 \%)$, to surgery.

Because no complication was noted during the 19 failed sessions, these procedures were excluded from the analysis and data from the remaining 827 procedures were analyzed.

Among 827 procedures, complications were reported in 206 (25\%), including HCs in $92(11 \%)$, postoperative ischemia in 53 (6\%), catheter entrapment in $49(6 \%)$, and catheter rupture in 12 (2\%). Overall complications were $27 \%$ in grade I, $24 \%$ in grade II, $28 \%$ in grade III, $25 \%$ in grade IV, and $29 \%$ in grade V.

Among 408 patients, permanent disability was seen in 5\% of S-M grade I, 6\% of S-M grade II, 14\% of S-M grade III, 19\% of $\mathrm{S}-\mathrm{M}$ grade IV, and $21 \%$ of S-M grade V. Fatal events occurred in $0 \%$ of S-M grades I and II, in 3\% of S-M grade III, in 1\% of S-M grade IV, and in $5 \%$ of $\mathrm{S}-\mathrm{M}$ grade $\mathrm{V}$.

\section{Table 1: Basic characteristics of patients and AVMs}

\begin{tabular}{lc}
\hline \multicolumn{1}{c}{ Variable $^{\mathbf{a}}$} & Patients $(\boldsymbol{n}=\mathbf{4 0 8})$ \\
\hline Age (yr) & $33.3 \pm 14.1$ \\
Men & $230(56)$ \\
Presenting symptoms & $196(48)$ \\
Hemorrhage & $115(28)$ \\
Seizure & \\
Spetzler-Martin grade & $41(10)$ \\
I & $124(30)$ \\
II & $143(35)$ \\
III & $81(20)$ \\
IV & $19(5)$ \\
V & \\
AVM location & $312(76)$ \\
Cortical & $66(16)$ \\
Deep & $30(7)$ \\
Infratentorial & $231(59)$ \\
Eloquent & \\
AVM characteristics & $159(39)$ \\
Deep drainage & $55(14)$ \\
Intranidal aneurysm & $157(38)$ \\
Number of procedure & $118(29)$ \\
1 Session & $75(18)$ \\
2 Sessions & $58(14)$ \\
3 Sessions & \\
$\geq 3$ Sessions & \\
\hline a . (\%) mean + SD &
\end{tabular}

\section{Characteristics of Hemorrhagic Complications}

Hemorrhagic complications occurred in 92 of 827 (11.1\%) procedures: $20 \%$ of S-M grade I, $11 \%$ grade II, $12 \%$ grade III, $8 \%$ grade IV, and $12 \%$ grade $\mathrm{V}$ (Table 2 ).

Forty-four (48\%) HCs were classified as related to an AP, of which the most frequently reported was subarachnoid hemorrhage $(71 \%)$. In most cases, the hemorrhage was detected during the procedure. Forty-eight (52\%) HCs were classified as NAP, 39 $(81 \%)$ of which occurred in the hours or days following the procedure (mean time between procedure and event, $34.4 \pm 50.1$ hours). Thirty-four of the NAP cases (71\%) were intraparenchymal hemorrhage. The HCs in the NAP group were located more commonly in cerebral parenchyma compared with the AP group. Eight HCs (17\%) occurred following a premature venous occlusion.

\section{Outcomes of Hemorrhagic Complications}

Procedures with HCs were associated with a new disability that was persistent at 1 month in 31 cases (patient morbidity related to an $\mathrm{HC}$ of $7.6 \%$ ). Death occurred in 6 patients with HCs (patient mortality related to an $\mathrm{HC}$ of $1.6 \%$ ) and in none of those without. As shown in Tables 2 and 3, compared with AP events, NAP events more commonly caused neurologic deficits and were associated with a worse prognosis ( $\mathrm{mRS}>2$ ). Despite more deaths occurring in the NAP group, there was no statistical difference between the 2 groups.

In the AP group, 12 patients showed a new neurologic deficit after the procedure, which was transient in 9 , and 1 death occurred.

In the NAP group, 37 patients showed a new neurologic deficit, including 28 cases (58\%) of permanent disability; 5 (10\%) patients died. Twenty-one (44\%) patients were independent $(\mathrm{mRS}<2)$ at the time of discharge.

\section{Risk Factors for Hemorrhagic Complication in the NAP Group}

Premature venous occlusion $(P<.001)$, volume of Onyx injected $(P<.02)$, total volume of embolic agent $(P<.03)$, ratio of Onyx volume to the largest diameter of the nidus $(P<.01)$, and ratio of $\mathrm{V}_{\mathrm{ea}}$ to the largest diameter of nidus $(P<.01)$ were associated with $\mathrm{HC}$ in univariate analysis (Table 4 ). Only premature venous oc-

Table 2: Characteristics of procedures with hemorrhagic complications

\begin{tabular}{|c|c|c|c|c|}
\hline Variable $^{a}$ & Overall $(n=92)$ & $\operatorname{AP}(n=44)$ & $\operatorname{NAP}(n=48)$ & $P$ Value \\
\hline \multicolumn{5}{|l|}{ AVM location } \\
\hline Cortical & $77(84)$ & $41(93)$ & $36(75)$ & $<.041$ \\
\hline Deep & $11(12)$ & $3(7)$ & $8(17)$ & \\
\hline Infratentorial & $4(4)$ & $0(0)$ & $4(8)$ & \\
\hline Eloquent & $53(58)$ & $17(39)$ & $36(75)$ & $<.001$ \\
\hline \multicolumn{5}{|l|}{ Type of HC } \\
\hline Intraparenchymal hemorrhage & $46(50)$ & $12(27)$ & 34 (71) & $<.001$ \\
\hline Subarachnoid hemorrhage & $35(38)$ & $31(71)$ & $4(8)$ & \\
\hline Intraventricular hemorrhage & $11(12)$ & $1(1)$ & $10(21)$ & \\
\hline \multicolumn{5}{|l|}{ Timing of rupture } \\
\hline Hemorrhage during procedure & $52(59)$ & $43(98)$ & $9(18)$ & $<.001$ \\
\hline Delay between procedure and hemorrhagic events, hours (range) & $17.2(0-240)$ & $0.05(0-2)$ & $34.4(0-240)$ & $<.001$ \\
\hline $\begin{array}{l}\text { Craniotomy for hematoma evacuation, decompressive } \\
\text { craniotomy or EVD }\end{array}$ & $15(16)$ & $3(7)$ & $12(25)$ & $<.019$ \\
\hline
\end{tabular}

Note:-EVD indicates external ventricular drainage.

${ }^{a}$ No. $(\%)$, mean \pm SD or range. 
Table 3: Outcomes in procedures with versus without hemorrhagic complications

\begin{tabular}{|c|c|c|c|c|c|c|c|}
\hline \multirow[b]{2}{*}{ Variable $^{a}$} & \multirow{2}{*}{$\begin{array}{l}\text { Overall } \\
(n=827)\end{array}$} & \multirow{2}{*}{$\begin{array}{c}\text { Without HC } \\
(n=735)\end{array}$} & \multirow{2}{*}{$\begin{array}{l}\text { With HC } \\
(n=92)\end{array}$} & \multirow{2}{*}{$\begin{array}{c}P \text { Value } \\
{\text { (without vs with } \mathrm{HC})^{\mathrm{b}}}^{\mathrm{b}}\end{array}$} & \multicolumn{3}{|c|}{ Type of Hemorrhagic Complications } \\
\hline & & & & & $\operatorname{AP}(n=44)$ & $\operatorname{NAP}(n=48)$ & $P$ Value (AP vs NAP) ${ }^{b}$ \\
\hline New disability & $127(15)$ & $78(11)$ & $49(53)$ & $<.001$ & $12(27)$ & $37(77)$ & $<.001$ \\
\hline Transient & $71(9)$ & $53(7)$ & $18(20)$ & & $9(20)$ & $9(19)$ & \\
\hline Permanent & $56(7)$ & $25(3)$ & $31(34)$ & & $3(7)$ & $28(58)$ & \\
\hline Death & $6(1)$ & $0(0)$ & $6(7)$ & $<.001$ & $1(2)$ & $5(10)$ & $<.207$ \\
\hline
\end{tabular}

${ }^{\mathrm{a}}$ No. (\%).

${ }^{\mathrm{b}} \chi^{2}$ or Fisher exact test for cells $<5$.

Table 4: Univariate predictors of hemorrhagic complications

\begin{tabular}{|c|c|c|c|}
\hline Variable $^{a}$ & $\begin{array}{c}\text { No Hemorrhagic } \\
\text { Complications }(n=735)\end{array}$ & $\begin{array}{c}\text { NAP } \\
(n=48)\end{array}$ & $\begin{array}{c}P \\
\text { Value }\end{array}$ \\
\hline Age (yr) & $32.2 \pm 13.7$ & $33.9 \pm 14.4$ & .405 \\
\hline Hemorrhagic presentation & $316(43)$ & $18(38)$ & .419 \\
\hline Nidus diameter $(\mathrm{cm})$ & $4.1 \pm 3.8$ & $3.9 \pm 3.5$ & .553 \\
\hline Spetzler-Martin grade ${ }^{b}$ & III & III & .874 \\
\hline AVM involving eloquent area & $443(60)$ & $36(75)$ & .164 \\
\hline Deep venous drainage & $317(43)$ & $21(44)$ & .660 \\
\hline Intranidal aneurysm presence & $107(15)$ & $6(13)$ & .513 \\
\hline Venous stenosis & $40(5)$ & $5(10)$ & .227 \\
\hline Venous ectasia & $372(51)$ & $25(3)$ & .596 \\
\hline Premature venous occlusion & $3(0.4)$ & $8(17)$ & $<.001$ \\
\hline Complete occlusion of AVM & $181(25)$ & $18(38)$ & .114 \\
\hline Detachable microcatheter & $127(17)$ & $7(15)$ & .606 \\
\hline Onyx volume (mL) & $2.1 \pm 2.0$ & $2.9 \pm 1.9$ & $<.02$ \\
\hline Total embolic agent volume $(\mathrm{mL})^{c}$ & $2.5 \pm 1.9$ & $3.2 \pm 1.6$ & $<.03$ \\
\hline Ratio of Onyx volume $(\mathrm{mL}) /$ nidus diameter $(\mathrm{cm})$ & $0.6 \pm 0.6$ & $0.8 \pm 0.6$ & $<.01$ \\
\hline Ratio of $\mathrm{V}_{\text {ea }}(\mathrm{mL}) /$ nidus diameter $(\mathrm{cm})^{\mathrm{c}}$ & $0.7 \pm 0.6$ & $0.9 \pm 0.6$ & $<.01$ \\
\hline No. of pedicles embolized in each procedure ${ }^{b}$ & 1 & 1 & .629 \\
\hline
\end{tabular}

${ }^{a}$ Mean \pm SD (median) (interquartile range) or count (\%).

${ }^{\mathrm{b}}$ Median.

'Sum of Onyx and glue used in each procedure.

Table 5: Independent predictors of hemorrhagic events in AVM size subdivisions of the no arterial perforation group

\begin{tabular}{|c|c|c|c|c|}
\hline Variable & $\boldsymbol{\beta}$ & Odds Ratio & 95\% Confidential Interval & $P$ Value $^{\mathrm{a}}$ \\
\hline \multicolumn{5}{|l|}{ Small AVM ${ }^{\mathrm{b}}$} \\
\hline Premature venous occlusion & 3.8 & 44.3 & $4.24-462.04$ & $<.001^{\mathrm{c}}$ \\
\hline Total embolic agent volume & 0.3 & 1.4 & $1.07-1.85$ & $<.013^{c}$ \\
\hline Constant $^{d}$ & -3.6 & 0.03 & & $<.001$ \\
\hline \multicolumn{5}{|l|}{ Mid-size AVM ${ }^{b}$} \\
\hline Premature venous occlusion & 3.1 & 23.4 & $3.7-148.4$ & $<.002^{c}$ \\
\hline Constant $^{\mathrm{d}}$ & -2.7 & 0.06 & & $<.001$ \\
\hline \multicolumn{5}{|l|}{ Large AVM ${ }^{\mathrm{b}}$} \\
\hline Premature venous occlusion & 24.2 & $3.2^{-10}$ & .00 & $1.00^{\mathrm{e}}$ \\
\hline Constant $^{d}$ & -3.0 & 0.05 & & $<.001$ \\
\hline
\end{tabular}

a Binary logistic regression.

${ }^{\mathrm{b}}$ Small AVM, the largest diameter $\leq 3 \mathrm{~cm}$; mid-size AVM, the largest diameters $>3 \mathrm{~cm}$ and $\leq 6 \mathrm{~cm}$; large AVM, the largest diameter $>6 \mathrm{~cm}$.

c Significant.

${ }^{\mathrm{d}}$ A mathematic constant (no clinical interpretation).

e Nonsignificant.

clusion remained an independent predictor on multivariate analysis $(\beta=3.8 ; P<.001 ; 95 \% \mathrm{CI}, 11-175)$. If premature venous occlusion occurred during the procedure, the probability of HCs increased by 45 -fold.

\section{Risk Factors for Hemorrhagic Complications according to AVM diameter}

Both premature venous occlusion and total volume of embolic agents were independent risk factors on multivariate analysis only for small AVMs (Table 5). In the midsize AVMs, only premature venous occlusion was a risk factor of $\mathrm{HC}$ on univariate and multivariate analysis. In large AVMs, no variables were risk factors for
HCs. The ratio of Onyx volume to the largest diameter of the nidus was an independent predictor of premature venous occlusion on multivariate analysis $(\beta=$ $1.4 ; P<.002 ; 95 \%$ CI, $1.8-9.3)$.

\section{DISCUSSION}

In this series of 827 procedures, $11 \%$ were complicated by hemorrhage, which is consistent with the literature in which intracranial hemorrhage during or after the procedure was the most frequent complication of AVM embolization, reported in 2\%-12.5\% of procedures. ${ }^{8,9,11-15}$ Intracranial hemorrhage was the most common cause of new disability after EVT. ${ }^{16}$ Our strategy of embolization with curative intent in most patients leads to a higher cure rate compared with series with adjunctive embolization; nevertheless, this more aggressive approach could explain the higher rate of mortality and morbidity in this study. Periprocedural bleeding not only can causes neurologic deterioration but can also can result in poor outcome or death in many cases. ${ }^{9,11,13,14}$ Aggressive treatment and early evacuation of the hematoma has minimized the neurologic morbidity in severe cases. ${ }^{13,17,18}$ In our series, more than one-third of patients with HCs experienced a new permanent disability and a further $7 \%$ died. The overall rate of patient permanent morbidity due to a hemorrhagic complication following endovascular treatment for AVMs was, therefore, $7.6 \%$, and the mortality rate was $1.6 \%$.

Several studies classify HCs of AVM embolization into immediate (ie, occurring during or immediately after embolization) or delayed (occurring after uneventful and successful embolization and believed to be related to premature venous occlusion). ${ }^{7,8,12} \mathrm{We}$ included, in our study, any hemorrhage detected on immediate postprocedural CT or that occurred within the month following treatment. Almost half of the HCs were related to microwire or microcatheter perforation during navigation or arterial tear at catheter retrieval at the end of embolization, corresponding to a subarachnoid hemorrhage confirmed by flat panel CT with mostly a favorable outcome. In most instances, they are managed by reversal of heparin with protamine and lowering blood pressure, which 
can stop the bleeding, ${ }^{7}$ or they can be controlled by glue injection to prevent progression of hemorrhage. New detachable-tip catheters ${ }^{19}$ or techniques with a second microcatheter placed in the same artery ${ }^{20}$ are used for management of bleeding at retrieval of the wedged microcatheter. HCs occurring during catheterization are reported in $2 \%$ of EVT procedures, which is less than in our series (5\%); however, it is likely that some of these complications are not mentioned because of their minor clinical significance, because they tend not to have clinical sequelae. ${ }^{1,11,12,21}$ Also our standard technique of AVM treatment primarily uses Onyx and thus requires wire-directed navigation and dimethyl-sulfoxidecompatible catheters or detachable-tip microcatheters, which are stiffer. This navigation technique might account for the high incidence of periprocedural arterial perforation. Despite a benign prognosis in most cases, patients who develop HCs should be followed closely after the procedure to detect any hematoma progression or neurologic deterioration.

HCs not related to an arterial perforation clearly show different characteristics, with a delayed appearance, mostly symptomatic intraparenchymal hemorrhage, and with a much poorer clinical prognosis (58\% permanent disability and 10\% death).

Many terms from the surgical and endovascular literature have been proposed to explain the mechanisms of the NAP hemorrhagic group: normal perfusion breakthrough, ${ }^{22}$ venous overload, ${ }^{23}$ occlusive hyperemia, ${ }^{24}$ nidus congestion, ${ }^{6}$ venous occlusion by liquid embolic agents (Onyx or glue), progressive venous occlusion due to flow slowing and thrombosis, and inflammatory reaction or mural necrosis induced by the embolic material. ${ }^{7,9,11,12,25}$ The importance of impaired venous drainage in the appearance of postoperative hemorrhage is well-recognized. al-Rodhan et $\mathrm{al}^{24}$ reported that edema and hemorrhage after AVM resection are attributable to obstruction of the venous outflow system of brain tissue adjacent to the AVM, with subsequent worsening of the existing hypoperfusion and ischemia. The presence of impaired venous drainage before an operation has been recognized as a factor for the appearance of postoperative hemorrhage. ${ }^{26}$ The brain parenchyma rendered hypoxic or ischemic by longstanding venous hypertension may not tolerate the increase in arterial flow after AVM resection. Careful examination of AVM drainage patterns is thus mandatory, with AVMs with more extensive patterns of draining veins requiring greater preoperative embolization and a staged return of normal circulatory patterns.

Ovalle et $\mathrm{al}^{8}$ showed that of 13 potential factors, the volume of the embolic agent was the only one predictive of a delayed hemorrhagic complication. Our results agree with both univariate and multivariate analyses only in the subdivision of small AVMs $(\leq 3$ $\mathrm{cm})$. In addition, we identified premature occlusion of the venous outflow before complete obliteration of the nidus as an independent predictor of hemorrhage, especially in small and midsize AVMs $(\leq 6 \mathrm{~cm})$. We also found that a predictive factor of premature venous occlusion is the ratio of Onyx volume to the largest diameter of the nidus. Using cyanoacrylates, Picard et $\mathrm{al}^{9}$ reported that $80 \%$ of cases with a delayed hemorrhagic complication received $\geq 1 \mathrm{~mL}$ of glue, a much smaller quantity than commonly used now with Onyx (the mean volume by session was $2 \mathrm{~mL}$ in our study). This highlights the importance of careful delivery of liquid embolic agent and emphasizes the need for thorough anatomic and hemodynamic knowledge of the AVM compartment and veins draining the nidus. ${ }^{27}$ Venous deposition of the embolic agent can be difficult to see when a large volume has been injected or when multiple embolizations have already been performed because the attenuation of Onyx prevents visualization.

Our study has some limitations. It is a retrospective analysis of the angioarchitecture of AVMs and of EVT results, which might not be simple with interobserver and intraobserver variability. This, combined with the relative small sample size of HC groups, could affect the analysis of the complications or result in nonsignificant differences.

\section{CONCLUSIONS}

Hemorrhagic complications are the most common and severe events following cerebral AVM embolization. Our study shows that premature venous occlusion is an independent predictive factor of hemorrhagic complications. Attention to the volume of the embolic agent used and prevention of premature venous occlusion by refined angioarchitecture analysis and liquid embolic delivery during EVT may reduce the incidence of these events. With regard to the risk of flow imbalance resulting in increased intranidal pressure and secondary rupture, our angiographic anatomic knowledge of the venous outflow of AVMs remains insufficient. There is, thus, a need for improvement of a preprocedural anatomic description of the nidus and its venous drainage as well as development of new embolic agents not obscuring the visualization of the nidal and venous anatomy.

\section{ACKNOWLEDGMENTS}

Sophie Rushton-Smith, $\mathrm{PhD}$, provided editorial assistance in the final version of the manuscript and was funded by the authors. We thank Oriane Lambert and Said Akhlaghi for assistance in statistical analysis of the data of study.

Disclosures: Raphaël Blanc_UNRELATED: Consultancy: Covidien, ${ }^{*}$ Stryker.* Stock Options: Lazarus Effect. Silvia Pistocchi-UNRELATED: Consultancy: Covidien,* Stryker.* Bruno Bartolini-UNRELATED: Consultancy: Covidien, ${ }^{\star}$ Stryker. ${ }^{*}$ Michel Piotin—UNRELATED: Consultancy: Stryker,* Covidien.* Payment for Manuscript Preparation: Covidien, ${ }^{\star}$ Payment for Development of Educational Presentations: Covidien, ${ }^{*}$ Stock/Stock Options: Lazarus Effect. *Money paid to the institution.

\section{REFERENCES}

1. Mounayer C, Hammami N, Piotin M, et al. Nidal embolization of brain arteriovenous malformations using Onyx in 94 patients. AJNR Am J Neuroradiol 2007;28:518-23

2. Debrun GM, Aletich V, Ausman JI, et al. Embolization of the nidus of brain arteriovenous malformations with n-butyl cyanoacrylate. Neurosurgery 1997;40:112-20

3. Weber W, Kis B, Siekmann R, et al. Preoperative embolization of intracranial arteriovenous malformations with Onyx. Neurosurgery 2007;61:244-52, discussion 252-244

4. Morgan MK, Winder M, Little NS, et al. Delayed hemorrhage following resection of an arteriovenous malformation in the brain. J Neurosurg 2003;99:967-71

5. Spetzler RF, Hargraves RW, McCormick PW, et al. Relationship of perfusion pressure and size to risk of hemorrhage from arteriovenous malformations. J Neurosurg 1992;76:918-23

6. Steiger HJ, Bruckmann H, Mayer T, et al. Congested residual nidus after preoperative intranidal embolization in midsize cerebral ar- 
teriovenous malformations of $3-6 \mathrm{~cm}$ in diameter. Acta Neurochir (Wien) 2004;146:649-57

7. Haw CS, terBrugge K, Willinsky R, et al. Complications of embolization of arteriovenous malformations of the brain. J Neurosurg 2006; 104:226-32

8. Ovalle F, Shay SD, Mericle RA. Delayed intracerebral hemorrhage after uneventful embolization of brain arteriovenous malformations is related to volume of embolic agent administered: multivariate analysis of 13 predictive factors. Neurosurgery 2012;70:313-20

9. Picard L, Da Costa E, Anxionnat R, et al. Acute spontaneous hemorrhage after embolization of brain arteriovenous malformation with N-butyl cyanoacrylate. J Neuroradiol 2001;28:147-65

10. Spetzler RF, Martin NA. A proposed grading system for arteriovenous malformations. J Neurosurg 1986;65:476-83

11. Saatci I, Geyik S, Yavuz K, et al. Endovascular treatment of brain arteriovenous malformations with prolonged intranidal Onyx injection technique: long-term results in $\mathbf{3 5 0}$ consecutive patients with completed endovascular treatment course. J Neurosurg 2011: $115 ; 78-88$

12. Purdy PD, Batjer HH, Samson D. Management of hemorrhagic complications from preoperative embolization of arteriovenous malformations. J Neurosurg 1991;74:205-11

13. Keller E, Yonekawa Y, Imhof HG, et al. Intensive care management of patients with severe intracerebral haemorrhage after endovascular treatment of brain arteriovenous malformations. Neuroradiology 2002;44:513-21

14. Deruty R, Pelissou-Guyotat I, Mottolese C, et al. Therapeutic risk in multidisciplinary approach of cerebral arteriovenous malformations [in French]. Neurochirurgie 1996;42:35-43

15. Biondi A, Le Jean L, Capelle L, et al. Fatal hemorrhagic complication following endovascular treatment of a cerebral arteriovenous malformation: case report and review of the literature. J Neuroradiol 2006;33:96-104

16. Panagiotopoulos V, Gizewski E, Asgari S, et al. Embolization of intracranial arteriovenous malformations with ethylene-vinyl alcohol copolymer (Onyx). AJNR Am J Neuroradiol 2009;30:99-106

17. Iwama T, Yoshimura K, Keller E, et al. Emergency craniotomy for intraparenchymal massive hematoma after embolization of supratentorial arteriovenous malformations. Neurosurgery 2003;53: 1251-58, discussion 1258-60

18. Carvi y Nievas M, Haas E, Hollerhage HG. Severe intracranial bleedings during endovascular procedures: outcome of surgically treated patients. Neurol Res 2007;29:81-90

19. Maimon S, Strauss I, Frolov V, et al. Brain arteriovenous malformation treatment using a combination of Onyx and a new detachable tip microcatheter, SONIC: short-term results. AJNR Am J Neuroradiol 2010;31:947-54

20. Abud DG, Abud TG, Nakiri GS. Management of brain AVM procedural hemorrhagic complication by the "security" catheter technique. J Neuroradiol 2013:40;45-49

21. n-BCA Trail Investigators. N-butyl cyanoacrylate embolization of cerebral arteriovenous malformations: results of a prospective, randomized, multi-center trial. AJNR Am J Neuroradiol 2002;23: $748-55$

22. Spetzler RF, Wilson CB, Weinstein $\mathrm{P}$, et al. Normal perfusion pressure breakthrough theory. Clin Neurosurg 1978;25:651-72

23. Wilson CB, Hieshima G. Occlusive hyperemia: a new way to think about an old problem. J Neurosurg 1993;78:165-66

24. al-Rodhan NR, Sundt TJ, Piepgras DG, et al. Occlusive hyperemia: a theory for the hemodynamic complications following resection of intracerebral arteriovenous malformations. J Neurosurg 1993;78: $167-75$

25. Cronqvist M, Wirestam R, Ramgren B, et al. Endovascular treatment of intracerebral arteriovenous malformations: procedural safety, complications, and results evaluated by MR imaging, including diffusion and perfusion imaging. AJNR Am J Neuroradiol 2006;27: $162-76$

26. Schaller C, Urbach H, Schramm J, et al. Role of venous drainage in cerebral arteriovenous malformation surgery, as related to the development of postoperative hyperperfusion injury. Neurosurgery 2002;51:921-27, discussion 927-29

27. Yamada S, Brauer FS, Colohan ART, et al. Concept of arteriovenous malformation compartments and surgical management. Neurol Res 2004;26:288-300 